\title{
Self-assembly of a Columnar Polymeric Calcium Phosphinate derived from Camphene
}

\author{
William Henderson, ${ }^{*}, a$ Meto T. Leach, ${ }^{a}$ Brian K. Nicholson ${ }^{a}$ and Michal Sabat ${ }^{b}$ \\ a Department of Chemistry, University of Waikato, Private Bag 3105, Hamilton, New Zealand \\ ${ }^{b}$ Department of Chemistry, University of Virginia, Charlottesville, VA, USA
}

\begin{abstract}
(2,2-Dimethylbicyclo[2.2.1] hept-3-ylmethyl)phosphinic acid $\left(\mathrm{RPO}_{2} \mathrm{H}_{2}\right)$, readily prepared from camphene and hypophosphorous acid, formed a polymeric calcium salt $\left[\left\{\mathrm{Ca}\left(\mathrm{RPO}_{2} \mathrm{H}\right)_{2}\left(\mathrm{RPO}_{2} \mathrm{H}_{2}\right)\left(\mathrm{H}_{2} \mathrm{O}\right)\right\}_{n}\right]$. with both terminal and triply bridging phosphinate groups, and an overall columnar structure with an inorganic core and a pseudo-close-packed sheath of terpene moieties.
\end{abstract}

The self-assembly of novel nanostructures using metal phosphates, phosphonates and phosphinates is an area of significant current interest, since such materials have applications in catalysis, ion exchange and sorptive processes. ${ }^{1-4}$ Specific examples include molecular sieve alumino- and gallo-phosphates, layered phosphonates having the ability to undergo shape- ${ }^{5,6}$ and enantio-selective ${ }^{7}$ intercalation reactions, and a vanadium phosphate which adopts a novel chiral double-helix structure. ${ }^{8}$ To date, however, studies have been largely restricted to salts of relatively simple, sterically non-demanding organophosphorus acids.

We recently reported the high-yield synthesis of the phosphinic and phosphonic acids, $\mathrm{RPO}_{2} \mathrm{H}_{2} \mathrm{I}$ and $\mathrm{RPO}_{3} \mathrm{H}_{2} 2$ respectively ( $\mathrm{R}=2,2$-dimethylbicyclo[2.2.1]hept-3-ylmethyl), from inexpensive camphene (2,2-dimethyl-3-methylenebicyclo[2.2.1] heptane) and hypophosphorous (phosphinic) acid $\mathrm{H}_{3} \mathrm{PO}_{2} \cdot{ }^{9}$ Unfortunately, the attempted preparation of chiral 1 starting from $(R)(+)$-camphene yielded only racemic material, as a result of acid-catalysed racemisation of the camphene; the structural stability of the RH skeleton (compared to that of the parent camphene) does however suggest that optical resolution of the enantiomers of 1 and/or 2 may be possible. The ready availability of these new organophosphorus acids suggested that metal derivatives having both novel structures and potential for materials separations (including ultimately enantioselective separations) might be accessible. We wished to undertake preliminary investigations into the structural chemistry of such metal phosphinate salts, and some of these studies are presented here.

Reaction of the compound ( \pm )-1 $1+$ with 0.5 mol equivalent of $\mathrm{Ca}\left(\mathrm{NO}_{3}\right)_{2} \cdot 4 \mathrm{H}_{2} \mathrm{O}$ and an excess of urea (for $\mathrm{pH}$ control) for $5 \mathrm{~d}$ yielded a colourless solution which, upon slow evaporation, afforded colourless prismatic crystals. $\ddagger$ These were characterised as the polymeric calcium salt $\left[\left\{\mathrm{Ca}\left(\mathrm{RPO}_{2} \mathrm{H}\right)_{2}\left(\mathrm{RPO}_{2} \mathrm{H}_{2}\right)-\right.\right.$ $\left.\left.\left(\mathrm{H}_{2} \mathrm{O}\right)\right\}_{n}\right]$ on the basis of a single-crystal X-ray study. $\S$ Owing to the relatively poor quality of the crystals, and the disorder of the $\mathbf{R}$ groups, arising from librational effects and possibly also from superposition of $(+)$ and $(-)$ enantiomers, the structure

$\dagger$ Obtained by a modification of the previously reported route ${ }^{9}$ by treating camphene with $\mathrm{H}_{3} \mathrm{PO}_{2}$ ( $3 \mathrm{~mol}$ equivalents) in refluxing $\mathrm{Pr}^{\mathrm{i}} \mathrm{OH}$ with a catalytic amount of benzoyl peroxide. The ( \pm )-phosphinic acid 1 has been fully characterised by NMR spectroscopy, electrospray mass spectrometry and by a single-crystal structure, full details of which will appear elsewhere.

$\ddagger$ A solution of $\mathrm{Ca}\left(\mathrm{NO}_{3}\right)_{2} \cdot 4 \mathrm{H}_{2} \mathrm{O}(0.585 \mathrm{~g}, 2.48 \mathrm{mmol})$ with compound ( \pm$)-1(1.00$ $\mathrm{g}, 4.95 \mathrm{mmol})$ and urea $\left(1.5 \mathrm{~g}\right.$, excess) in reagent-grade methanol $\left(30 \mathrm{~cm}^{3}\right)$ was warmed to $65^{\circ} \mathrm{C}$ for $5 \mathrm{~d}$. The resulting solution was filtered to remove a small quantity of white solid, and the filtrate allowed spontaneously to evaporate, producing colourless needles which were filtered off, washed with cold methanol $\left(2 \times 10 \mathrm{~cm}^{3}\right)$ and air dried, to give a polymeric calcium salt $(0.568 \mathrm{~g}, 35 \%$ based on Ca) (Found: $\mathrm{C}, 54.1 ; \mathrm{H}, 9.7 . \mathrm{C}_{30} \mathrm{H}_{57} \mathrm{CaO}_{7} \mathrm{P}_{3}$ requires $\mathrm{C}, 54.4 ; \mathrm{H}, 8.7 \%$ ), fractures and turns opaque $>100^{\circ} \mathrm{C}$, softens $>210^{\circ} \mathrm{C},{ }^{31} \mathrm{P}-\left\{{ }^{1} \mathrm{H}\right\}$ NMR $\left(\mathrm{MeOH}, \mathrm{D}_{2} \mathrm{O}\right.$ external lock): $\delta 29.1(\mathrm{~s})$

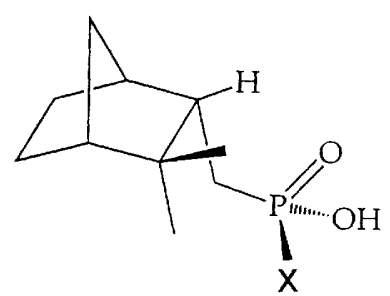

$1 \mathrm{X}=\mathrm{H}$
$2 \mathrm{X}=\mathrm{OH}$

determination is less precise than is usual $(R=0.148)$. A detailed discussion of bond parameters is therefore unfortunately precluded. Nevertheless, the overall structural features are clear and of interest.

The asymmetric unit formally consists of two $\mathrm{Ca}^{2+}$ ions, four $\mathrm{RPO}_{2} \mathrm{H}^{-}$anions, two $\mathrm{RPO}_{2} \mathrm{H}_{2}$ molecules, and two water molecules, linked to form a buckled ladder-like chain polymer. The co-ordination geometries about the $\mathrm{Ca}^{2+}$ ions are given in Fig. 1. Each of the crystallographically distinct, but chemically equivalent, $\mathrm{Ca}^{2+}$ ions is six-co-ordinate, being bonded to one $\mathrm{H}_{2} \mathrm{O}$ ligand, to two oxygen atoms from terminally bonded phosphinates, to two oxygen atoms which bridge symmetryrelated $\mathrm{Ca}^{2+}$ ions, and to one oxygen atom from a phosphinate which bridges between the two independent $\mathrm{Ca}^{2+}$ ions.

There are two types of phosphinate groups. Two of them in the backbone of the ladder [labelled $\mathrm{P}(5)$ and $\mathrm{P}\left(6^{\prime}\right)$ in Fig. 1] are present as the anion $\mathrm{RPO}_{2} \mathrm{H}^{-}$, and have one oxygen bonded terminally to one $\mathrm{Ca}^{2+}$ ion and the other oxygen doubly bridging the other $\mathrm{Ca}^{2+}$ ions. The other four ligands are terminally bonded, two to each of the two distinct $\mathrm{Ca}^{2+}$ ions. Formally, these are present as two $\mathrm{RPO}_{2} \mathrm{H}^{-}$and two $\mathrm{RPO}_{2} \mathrm{H}_{2}$, but the $\mathrm{OH}$ group of one ligand is hydrogen bonded to the free

§ Crystal data. $\mathrm{C}_{60} \mathrm{H}_{114} \mathrm{Ca}_{2} \mathrm{O}_{14} \mathrm{P}_{6}, M_{\mathrm{r}}=1325.57$, triclinic, space group $P \mathrm{I}, a=$ $12.501(3), b=18.154(4), c=18.474(4) \AA, \alpha=117.80(3), \beta=96.40(3), \gamma=$ $102.20(3)^{\circ}, U=3516.3(14) \AA^{3}, Z=2, D_{\mathrm{c}}=1.25 \mathrm{~g} \mathrm{~cm}^{3}, F(000)=1432, \mu(\mathrm{Cu}$ $\mathrm{K} \alpha)=31 \mathrm{~cm}^{-1}$, dimensions ca. $0.4 \times 0.12 \times 0.12 \mathrm{~mm}$. Data were measured at $-173^{\circ} \mathrm{C}$ on a Nicolet $\mathrm{R} 3$ diffractometer with graphite-monochromated $\mathrm{Cu}-\mathrm{K} x$ radiation $(\lambda=1.5418 \AA$ ) using $\omega$ scans. A total of 5302 reflections were collected with 4935 unique $\left(R_{\text {in }} 0.048\right)$. After absorption correction ( $\psi$-scan method $\left.T_{\max , \min } 0.96,0.66\right) 2834$ reflections had $I>2 \sigma(I)$. The structure was solved by direct methods to give the $\mathrm{Ca}^{2+}$ ion and the $\mathrm{P}$ atom positions, and a subsequent difference map revealed the $O$ atoms and the PCC carbons of the $R$ groups, which refined cleanly in subsequent cycles. The remaining parts of the $R$ groups showed significant disorder, so were refined with restrained C-C bond lengths of $1.54(5) \AA$. In the final cycles of least-squares refinement on $F^{2}$ only the $\mathrm{Ca}$ and $\mathrm{P}$ atoms were refined anisotropically, while all C-C distances were restrained to $1.54(5) \AA$. The $H$ atoms were not included. Convergence gave $R_{1}=0.148$ [for 2834 data with $I>2 \sigma(I)], 0.221$ (all data), and $w R_{2}=0.431$ (all data), where $w=\left[\sigma^{2}\left(F_{\mathrm{o}}{ }^{2}\right)+\right.$ $\left.(0.2072 P)^{2}+70.21 P\right]^{1}$ and $P=\frac{1}{3}\left(F^{2}+2 F^{2}\right)$. Goodness of fit was 1.027 Programs used were SHELXS $86^{10}$ and SHELXL 93. ${ }^{11}$ Atomic coordinates, thermal parameters and bond lengths and angles have been deposited at the Cambridge Crystallographic Data Centre. See Instructions for Authors, J. Chem Soc., Dalton Trans., 1995, Issue 1, pp. xxv-xxx. 


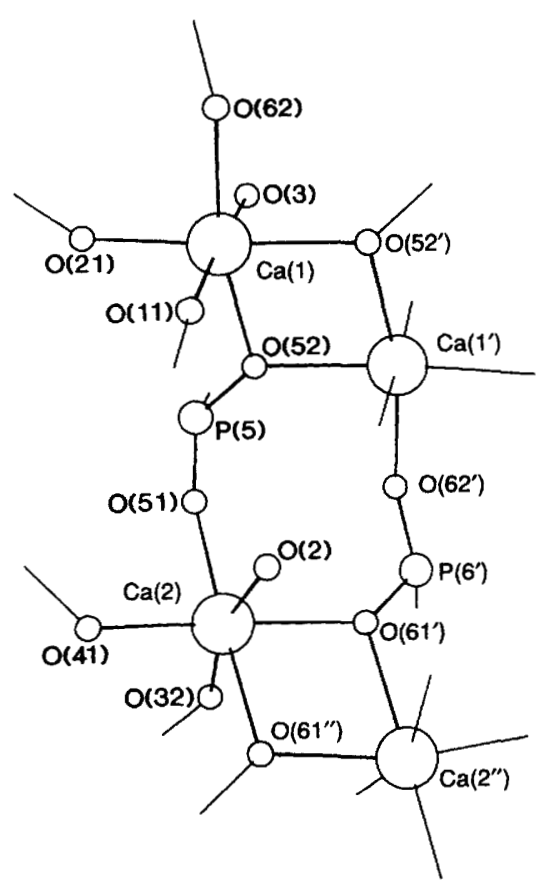

Fig. 1 Co-ordination geometry about the calcium atoms in the polymeric chain, showing the alternating four- and eight-membered rings and the atom numbering scheme. Selected bond lengths $(\AA)$ and angles ( $\left.{ }^{\circ}\right)$ : $\mathrm{Ca}(1)-\mathrm{O}(3)$ 2.413(13), $\mathrm{Ca}(2)-\mathrm{O}(2)$ 2.414(13), $\mathrm{Ca}(1)-\mathrm{O}(52)$ 2.361(13), $\mathrm{Ca}(1)-\mathrm{O}\left(52^{\prime}\right) \quad 2.366(12), \mathrm{P}(5)-\mathrm{O}(51) \quad 1.45(2), \mathrm{P}(5)-\mathrm{O}(52)$ 1.496(13), $\mathrm{Ca}(2)-\mathrm{O}(51)$ 2.26(2), $\mathrm{Ca}(1)-\mathrm{O}(11)$ 2.29(2), $\mathrm{Ca}(1)-\mathrm{O}(21)$ 2.34(2), $\mathrm{Ca}(2)-\mathrm{O}(32) 2.32(2), \mathrm{Ca}(2)-\mathrm{O}(41) 2.29(2) ; \mathrm{O}(52)-\mathrm{Ca}(1)-\mathrm{O}\left(52^{\prime}\right)$ 78.1(5), $\mathrm{Ca}(1)-\mathrm{O}(52)-\mathrm{Ca}\left(1^{\prime}\right)$ 101.9(5), $\mathrm{O}(51)-\mathrm{P}(5)-\mathrm{O}(52) 119.5(9), \mathrm{P}(5)-$ $\mathrm{O}(51)-\mathrm{Ca}(2)$ 158.9(11), $\mathrm{P}(5)-\mathrm{O}(52)-\mathrm{Ca}(1)$ 124.3(7), O(3)-Ca(1)-O(52') 81.4(4), $\mathrm{O}(11)-\mathrm{Ca}(1)-\mathrm{O}\left(52^{\prime}\right) 98.3(5)$

oxygen of an adjacent ligand, rendering them equivalent. The net result of these interactions is to generate a buckled ladder consisting of alternating four-membered $\mathrm{Ca}_{2} \mathrm{O}_{2}$ and eightmembered $\mathrm{Ca}-\mathrm{O}-\mathrm{P}-\mathrm{O}-\mathrm{Ca}-\mathrm{O}-\mathrm{P}-\mathrm{O}$ rings, supported by the $\mathrm{P}-\mathrm{O}-\mathrm{H} \cdots \mathrm{O}=\mathrm{P}$ hydrogen-bonding interactions between ligands on adjacent $\mathrm{Ca}^{2+}$ ions, which further serve to bind the chain together.

Inspection of a space-filling diagram, Fig. 2, clearly indicates the dominance of the bulky $R$ groups, which form a coherent, essentially 'close-packed' hydrocarbon sheath around the central hydrophilic inorganic $\mathrm{Ca} / \mathrm{O} / \mathrm{P}$ core. Individual chains therefore resemble an 'insulated wire'.

In contrast to metal phosphonates, relatively few metal derivatives of phosphinic (or dialkylphosphoric) acids have been structurally characterised, though chain polymers are common structural types for these types of materials. ${ }^{12}$ The presence of additional neutral co-ordinated phosphinic acids in the present compound appears to be a new feature in the structural chemistry of such systems, and it seems reasonable to propose that the self-assembly is being largely directed by the space-filling requirements of the bulky $\mathbf{R}$ moieties.

Crystals of the polymer are soluble in methanol, and the ${ }^{31} \mathrm{P}-$ $\left\{{ }^{1} \mathbf{H}\right\}$ NMR spectrum of the resulting solution shows a single peak at $\delta 29.1$, close to the predicted weighted-average position for two $\mathrm{RPO}_{2} \mathrm{H}^{-}(\delta c a .26 .5)$ and a $\mathrm{RPO}_{2} \mathrm{H}_{2}(\delta 35.4)$, indicating that the polymeric structure is not retained in solution.

The simple synthesis of this self-assembled hybrid inorganicorganic structure suggests that other metal salts of these phosphinic and phosphonic acids will display interesting structural features, and these are currently under investigation.

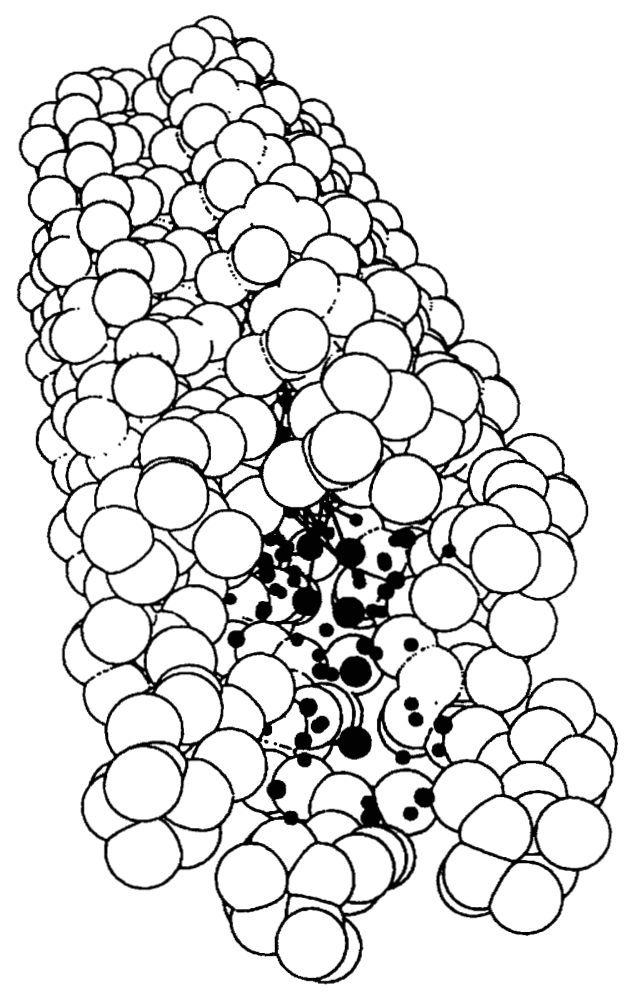

Fig. 2 Space-filling representation of the polymeric chain, with calcium, phosphorus and oxygen atoms of the central hydrophilic core shown by the smaller black circles, and the carbon atoms of the R group by the larger open circles

\section{Acknowledgements}

We thank the University of Waikato for financial support, Professor W. T. Robinson (University of Canterbury) for X-ray data collection, and the New Zealand Lottery Grants Board for a grant-in-aid towards purchase of a mass spectrometer.

\section{References}

1 M. E. Thompson, Chem. Mater., 1994, 6, 1168.

2 S. L. Suib, Chem. Rev., 1993, 93, 803.

3 G. Cao, H.-G. Hong and T. E. Mallouk, Acc. Chem. Res., 1992, 25, 420.

4 A. Clearfield, Comments Inorg. Chem., 1990, 10, 89.

5 G. Cao, V. M. Lynch and L. N. Yacullo, Chem. Mater., 1993, 5, 1000.

6 G. Cao and T. E. Mallouk, Inorg. Chem., 1991, 30, 1434.

7 G. Cao, M. E. Garcia, M. Alcalá, L. F. Burgess and T. E. Mallouk, J. Am. Chem. Soc., 1992, 114, 7574.

8 V. Soghomonian, Q. Chen, R. C. Haushalter, J. Zubieta and C. J. O'Connor, Science, 1993, 259, 1596.

9 W. Henderson and P. A. T. Hoye, UK Pat. Appl., GB 2268178 , 1994; Chem. Abstr., 1994, 120, $323861 x$.

10 G. M. Sheldrick, SHELXS 86, Program for the solution of crystal structures, University of Göttingen, 1986.

11 G. M. Sheldrick, SHELXL 93, Program for the refinement of crystal structures, University of Göttingen, 1993.

12 See, for example, W. T. A. Harrison, T. M. Nenoff, T. E. Gier and G. D. Stucky, Inorg. Chem., 1992, 31, 5395; S.-J. Liu, R. J. Staples and J. P. Fackler, jun., Polyhedron, 1992, 11, 2427; M. Shieh, K. J. Martin, P. J. Squattrito and A. Clearfield, Inorg. Chem., 1990 , 29, 958; P. Colamarino, P. L. Orioli, W. D. Benzinger and H. D. Gillman, Inorg. Chem., 1976, 15, 800.

Received 8th March, 1995; Communication 5/01436K 